\section{From the Editor's desk}

By Peter Tyrer

\section{The merits of a global perspective}

It has almost become a pointless mantra to repeat 'we are now international' but there is important substance to the wish for a more global perspective in psychiatry. For those involved in developing community services it is amazing to follow the time change zones round the world. In the Czech Republic services are at the stage we were in the UK in 1977, in Slovakia it is 1972, in the Ukraine it is 1965, in Rwanda 1964, in Tibet 1960 and in Belarus 1953. So why not take advantage of this time warp and help Belarus now to develop the best possible services from the 50 extra years of accumulated knowledge? The reverse is also true. We can test hypotheses now that we might have considered many years ago by looking at the experiences of other countries. Schizophrenia remains difficult to treat and much concern has been expressed about its excess mortality, particularly the suspicion that this is a consequence of antipsychotic drug treatment. ${ }^{1}$ These drugs may lead to obesity, a growing problem with increasing age (Kivimäki et al, pp.149-155), and its associated metabolic syndrome., ${ }^{2,3}$ In low- and middle-income countries our view of outcome has been influenced greatly by data from Chandigarh in North India, where better results may be related to different family structures with low expressed emotion, conferring protection. ${ }^{4}$ But long-term outcome is poor in such countries also ${ }^{5}$ and Ran et al (pp. 126-131) suggest that those never treated for schizophrenia, even though they may have received traditional remedies, ${ }^{6}$ have the same mortality as those treated with Western evidence-based interventions. When we get consistency across very different countries we can have much more confidence in our conclusions, and the association of urbanicity and schizophrenia first identified by Faris \& Dunham 70 years ago, ${ }^{7}$ and repeatedly identified in all population groups, ${ }^{8}$ now seems to have its final badge of approval from Lundberg et al (pp. 156-162) in their study from Uganda. I cannot help noticing from their paper that grandiosity as a psychotic experience is a marked distinguishing feature between urban and rural rearing; perhaps being surrounded by all those tall city buildings unduly raises expectations. We need to be reminded that increased mortality is also common in other psychiatric disorders. This is illustrated in depression by Mykletun et al (pp.118-125), who also intriguingly find that greater trait anxiety increases your lifespan, so perhaps there is some gain from constant worry and increased help-seeking behaviour.

Both deviations and consistency in cross-national studies can help us with diagnosis in psychiatry, a subject still looking for a modern-day Linnaeus to show the way forward. Schizotypy is regarded as a personality disorder in the DSM classification but sits within the schizophrenia spectrum in the ICD. Data from Lahti et al (pp. 132-137) suggest the ICD classification is nearer the truth, but in their discussions of vulnerability factors we need to be aware of the dangers of oversimplified interpretations of epidemiological findings from large data-sets. Only some associations are causal and these need to be tested and confirmed by appropriate experimental designs: Thapar \& Rutter (pp.100-101) remind us of this in their valuable editorial.

If we are global in outlook, we may sometimes appear to neglect our home-grown produce, even if it is of high standard, on the grounds that it is of local interest only. Some of our contributors are unhappy about this balance, but I would like to reassure them that what might appear to be parochial is highly publishable if it can still command widespread international interest. The paper on the long-term outcome in children of the bushfire disaster in South Australia by McFarlane \& Van Hooff (pp.142-148) could appear to have limited interest outside Australia; but the unusual design, with a comparison group recruited at the time of the disaster, makes the results relevant to a much wider audience. The finding of a relatively modest impact of the disaster on the adult psychopathology of the children exposed to the fire shows the remarkable resilience of most children. It probably also reflects the positive attributes of the downbeat Aussie response to negative events, 'that'd be right', the successful overcoming of which has been summarised nicely by Rutter, 'the promotion of resilience does not lie in an avoidance of stress, but rather in encountering stress at a time and in a way that allows self-confidence and social competence to increase through mastery and appropriate responsibility'9 (p. 608). This augurs well for the long-term outcome of the latest bushfire tragedy that devastated South Australia early in 2009.

\section{Expanding our international journals}

In the 2059 equitable world order we might expect to see the Chinese Journal of Psychiatry heading the list of mental health journals by impact factor with the Archives of General Psychiatry lagging behind a little and with the British Journal of Psychiatry in the second division. This would reflect both the importance and relevance of world psychiatric research and allow all of us to celebrate as members of a global community. We are genuinely in the business of promoting our competitors and are making great strides in so doing, ${ }^{10}$ even though in the long term they may come alongside or overtake us. The key aim is to expand dissemination of good research and practice, not to lionise individual publications. World Psychiatry is making a good start to this with its 2008 impact factor of 3.9, not far short of our own journal. I am glad that in our search for excellence we are now leaving behind local considerations and can also dispense with the Gilbertian criticism of equity from The Gondoliers,

'In short, wherever you may be, with this conclusion you'll agree When everyone is somebody, then no one's anybody.'

1 Joukamaa M, Heliövaara M, Knekt P, Aromaa A, Raitasalo R, Lehtinen V. Schizophrenia, neuroleptic medication and mortality. Br J Psychiatry 2006; 188: $122-7$.

2 Mackin $\mathrm{P}$, Bishop D, Watkinson $\mathrm{H}$, Gallagher $\mathrm{P}$, Ferrier IN. Metabolic disease and cardiovascular risk in people treated with antipsychotics in the community. Br J Psychiatry 2007; 191: 23-9.

3 Taylor DM, Douglas-Hall P, Olofinjana B, Whiskey E, Thomas A. Reasons for discontinuing clozapine: matched, case-control comparison with risperidone long-acting injection. Br J Psychiatry 2009; 194: 165-7.

4 Leff J, Wig NN, Ghosh A, Bedi H, Menon DK, Kuipers L, et al. Expressed emotion and schizophrenia in north India. III. Influence of relatives' expressed emotion on the course of schizophrenia in Chandigarh. Br J Psychiatry 1987; 151: $166-73$.

5 Ran M-S, Chen EY-H, Conwell Y, Chan CL-W, Yip PSF, Xiang M-Z, et al. Mortality in people with schizophrenia in rural China: 10-year cohort study. Br J Psychiatry 2007; 190: 237-42.

6 Rathbone J, Zhang L, Zhang $\mathrm{M}$, Xia J, Liu X, Yang Y, et al. Chinese herbal medicine for schizophrenia. Cochrane systematic review of randomised trials. Br J Psychiatry 2007; 190: 379-84.

7 Faris RE, Dunham HW. Mental Disorders in Urban Areas. University of Chicago Press, 1939

8 Kirkbride JB, Barker D, Cowden F, Stamps R, Yang M, Jones PB, et al. Psychoses, ethnicity and socio-economic status. Br J Psychiatry 2008; 193 18-24.

9 Rutter M. Resilience in the face of adversity. Protective factors and resistance to psychiatric disorder. Br J Psychiatry 1985; 147: 598-611.

10 de Jesus Mari J, Patel V, Kieling C, Anders M, Jakovljevi M, Lam LC, et al. The 5/95 Gap on the dissemination of mental health research: The World Psychiatric Association (WPA) task force report on project with editors of low and middle income (LAMI) countries. Afr J Psychiatry (Johannesbg) 2009; 12: 33-9. 